\title{
A SIMPLE COLORIMETRIC DETECTOR OF SYMMETRIC 2-(DIALKYLAMINO)ETHANETHIOLS AS PRECURSORS OF V-TYPE NERVE AGENTS
}

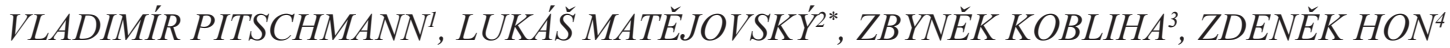

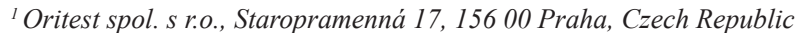 \\ ${ }^{2}$ Faculty of Environmental Protection Technology, Institute of Chemical Technology, \\ Technická 5, 16628 Praha, Czech Republic, \\ ${ }^{3}$ The NBC Defence Institute of the University of Defence, Sídišsě Vita Nejedlého 692, 68201 Vyškov-Dédice, Czech Republic \\ ${ }^{4}$ Faculty of Biomedical Engineering, Czech Technical University in Prague, Sitná 3105, 27201 Kladno, Czech Republic
}

\begin{abstract}
A colorimetric detector tube of 2-(dialkylamino)ethanethiols as precursors of V-type nerve agents and their hydrolytic products was designed. The detector is based on a reaction of 2-(dialkylamino)ethanethiols with a chromogenic reagent 4-chloro-7-nitrobenzofurazan (NBD-Cl) in alkaline medium leading to characteristic coloured products. The detection limit in water is of $5 \mu \mathrm{g} / \mathrm{ml}$, the optimum measurement range being up to $250 \mu \mathrm{g} / \mathrm{ml}$. The detector also presented a response to some other warfare chemical agents, the colour shade being, however, different. Effects of disturbing substances and organic solvents were studied.
\end{abstract}

Key words: colorimetric detector, analysis of water, 2-(dialkylamino)ethanethiols, V-type nerve agents, 4-chloro-7-nitrobenzofurazan.

\section{INTRODUCTION}

Symmetric 2-(dialkylamino)ethanethiols having the general formula $\mathrm{R}_{2} \mathrm{NCH}_{2} \mathrm{CH}_{2} \mathrm{SH}$ are chemical agents, presenting a considerable risk to targets of the Chemical Weapons Convention (List 2B). They can be used as precursors in the final synthesis of highly toxic V-type nerve agents, potent inhibitors of acetylcholine esterase. In the past, two members of this group of nerve agents were industrially manufactured: substance VX, i.e. $S$-[2(diisopropylamino)ethyl]-O-ethyl-methylphosphonothiolate and substance VR (R-33), i.e. $S$-[2-(diethylamino)ethyl]- $O$-isobutyl-methylphosphonothiolate ${ }^{1,2}$. For their synthesis, it is possible to use 2-(diisopropylamino)ethanethiol and 2-(diethylamino)ethanethiol, respectively. For an outline of most frequently used aminothiols as precursors of V-type agents see Table 1. On the other hand, these aminothiols are also produced by the hydrolysis of V-type agents, as shown schematically in Figure 1.

Table 1. Outline of most important 2-(dialkylamino)ethanethiol groups of V-type agents ${ }^{3,4}$.

\begin{tabular}{|c|c|}
\hline Group & Agent V \\
\hline$-\mathrm{SCH}_{2} \mathrm{CH}_{2} \mathrm{~N}\left(\text { iso- } \mathrm{CHCH}_{3} \mathrm{CH}_{3}\right)_{2}$ & VX, VS \\
\hline$-\mathrm{SCH}_{2} \mathrm{CH}_{2} \mathrm{~N}\left(\mathrm{CH}_{2} \mathrm{CH}_{3}\right)_{2}$ & $\begin{array}{c}\text { VR (R-33), VM, VE, VG, EA-3148 } \\
\text { (agent 100A), agent 100B }\end{array}$ \\
\hline$-\mathrm{SCH}_{2} \mathrm{CH}_{2} \mathrm{~N}_{\left(\mathrm{CH}_{3}\right)_{2}}$ & $25 \mathrm{SN}$ (medemo) \\
\hline
\end{tabular}

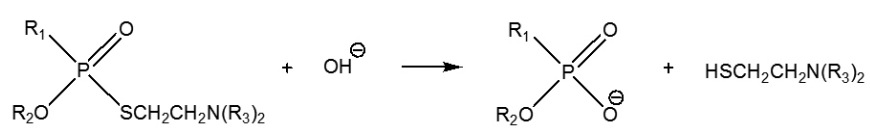

Figure 1. Scheme of V-type agents hydrolysis.

Monitoring of the manufacture, processing and consumption of 2-(dialkylamino)ethanethiols is of importance in terms of restricting the risk of their military or terroristic misuse. The monitoring process also includes their chemical analysis taking advantage of a variety of instrumental methods as well as relatively simple procedures, including methods based on reducing effects accompanied by colour changes ${ }^{5}$. For the detection and determination of 2-(dialkylamino)ethanethiols and structurally similar substances, it is for example possible to use their reactions with iodine, potassium permanganate, 4,4'-bis(dimethylamino)benzophenone oximes, quinone oximes, tetrazolium compounds (triphenyltetrazolium chloride, Tetrazolium Blue $)^{6}$, Folin-Ciocalteu reagent ${ }^{7}$ or with further reagents ${ }^{8,9}$. The obviously most frequently used approach is a classical method based on the reduction of the Ellman reagent or its analogues leading to colour products ${ }^{10-12}$. For the spectrophotometric determination, certain triphenylmethane dyes were also proposed (Guinea Green, Malachite Green), which are decolourized by the action of 2-(dialkylamino)ethanethiols ${ }^{13}$.

The objective of the work presented here was to design a simple method of the detection of 2-(dialkylamino)ethanethiols in water and aqueous solutions by using the technique of detector tubes which does not call for any processing of the sample and reaction medium compared to known methods and is characterized by a high selectivity degree. 4-chloro-7-nitrobenzofurazan (NBD-Cl) was proposed as a chromogenic reagent, which has been known in previous works aimed at the analysis of different compounds bearing thiol or amino groups ${ }^{14-18}$. This method can supplement commonly used electronic devices (such as AP2C detectors), and can be useful in chemical emergencies or for first responses. This will contribute to the efforts of the Organization for the Prohibition of Chemical Weapons in the peaceful uses of chemistry.

\section{EXPERIMENTAL}

\subsection{Chemicals and equipment}

For the preparation of detector filling, 98\% 4-chloro-7-nitrobenzofurazan (NBD-Cl), analytical grade sodium carbonate (both Sigma-Aldrich, USA), anhydrous ethanol (Riedel de Haen) and redistilled water were used. Silica gel (Grace, Germany) and ground porcelain (Tejas, Czech Republic) served as carriers. Glass packing tubes, internal diameter of $5 \mathrm{~mm}$, polyethylene sealing and distributing elements and polyamide nets (Tejas, Czech Republic) were used to construct the detectors. As model agents, $98.3 \% 2$-(diisopropylamino) ethanethiol hydrochloride (DIAET, University of Defence, Czech Republic), 95\% 2-(diethylamino)ethanethiol hydrochloride (DEAET) and $95 \%$ 2-(dimethylamino)ethanethiol hydrochloride (DMAET), both Sigma-Aldrich, USA, were detected. Spectrophotometric measurements were carried out by using the portable LMG 173 tristimulus colorimeter (Dr. Lange, Germany).

\subsection{Preparation of carriers, fillings and detector}

Silica gel, particle size of 0.7 to $0.9 \mathrm{~mm}$, was thoroughly purified with $10 \%$ hydrochloric acid, rinsed with redistilled water till neutral $\mathrm{pH}$ was achieved and activated at $130^{\circ} \mathrm{C}$. Ground porcelain, particle size of 0.7 to $1.0 \mathrm{~mm}$, was purified with water containing an admixture of a detergent and then thoroughly rinsed with redistilled water.

The indication layer was prepared by the impregnation of silica gel with $2.5 \%$ aqueous sodium carbonate solution. One hundred and ten $\mathrm{ml}$ of the solution was necessary per $100 \mathrm{~g}$ of silica gel. The impregnated mixture was dried at $110^{\circ} \mathrm{C}$ for 4 hours. An auxiliary layer was prepared by the impregnation of ground porcelain with $1 \%$ solution of the chromogenic reagent NBD-Cl in ethanol. Twenty five $\mathrm{ml}$ of the solution was necessary per $100 \mathrm{~g}$ of the carrier. The impregnated carrier was air-dried.

The detector was formed by a glass packing tube filled with the indication and auxiliary layers (in this sequence). Both layers, $10 \mathrm{~mm}$ long, were fixed to prevent their motion with polyethylene elements and separated from each other by a polyamide net. The tube was sealed at both ends. For a scheme of the detector tube design see Figure 2. 


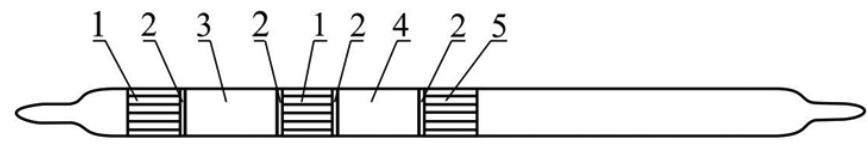

Figure 2. Detector scheme (1 - polyethylene element, 2 - polyamide net, 3 - indication layer, 4 - auxiliary layer, 5 - conical polyethylene element).

\subsection{Testing of detectors and their evaluation}

For testing, stock solutions prepared by dissolving $0.1 \mathrm{~g}$ of particular 2-(dialkylamino)ethanethiols (DMAET, DEAET, DIAET) in $100 \mathrm{~cm}^{3}$ of water were used. The working solutions were prepared by dilution. Freshly prepared solutions were used for each procedure. The sample purity was controlled by titration with a mercuric chloride solution, by using the potentiometric indication with a sulphide ISE ${ }^{19}$.

The detector was open by breaking off both tips and immersed into the liquid sample examined in such a way that the end containing the indication filling was directed downward. Both layers were saturated with the sample examined. After one minute, the liquid from the auxiliary layer was taken down to the indication layer to rinse the reagent and reaction product. After $15 \mathrm{~min}$, the colour of the indication layer was visually evaluated in daylight. A similar procedure was also employed in the study of reaction conditions and other detector parameters.

The detection limit was established as the lowest concentration of 2-(dialkylamino)ethanethiols, at which a visually perceptible change in the detector colour was observed compared to blank. The detection limit was determined by measuring a series of 20 samples of known concentrations at a probability limit of $\mathrm{P}=0.05$ ( $95 \%$ confirmation of the concentration). The upper limit of the measurement range corresponded to the maximum concentration of 2-(dialkylamino)ethanethiols which can still be visually proportionally differentiated.

\section{RESULTS AND DISCUSSION}

\subsection{Mechanisms of the reaction and colour characteristic}

The colorimetric detector of 2-(dialkylamino)ethanethiols proposed here was based on their reactions with $\mathrm{NBD}-\mathrm{Cl}$ in alkaline medium yielding green reaction products. In accordance with reference ${ }^{13}$, the proposed scheme of the reaction of 2-(dialkylamino)ethanethiols with the reagent is shown in Figure 3. Competing reactions producing Meisenheimer complexes or oxidation reactions can simultaneously occur ${ }^{20}$.

The onset and dynamics of the colouration considerably depended on the 2-(dialkylamino)ethanethiol concentration in the sample. At concentrations above $100 \mu \mathrm{g} / \mathrm{ml}$, the colour appeared very rapidly. The complete coloration of the indication layer established visually was achieved within $15 \mathrm{~min}$ after the exposure. The dependence of the colour intensity on time as measured by the objective method of tristimulus colorimetry is shown in Figure 4, where (-)a is a negative value on the green chromatic axis in the CIE-Lab colour system.<smiles>[R]N([R])CC[AsH2-]CCSc1ccc(Cl)c2nonc12</smiles>
$\mathrm{NaCl}$

Figure 3. Scheme of reaction of 2-(dialkylamino)ethanethiols with NBD$\mathrm{Cl}$.

\subsection{Reaction conditions and temperature effects}

Colour reactions of NBD-Cl with 2-(dialkylamino)ethanethiols occurred in neutral and moderately alkaline medium only. In strongly alkaline medium, undesirable competing reactions occurred, and a colour NBD-Cl hydroxyderivative was also likely to be produced ${ }^{17}$. The dependence of the colour intensity on contents of sodium carbonate in the indication layer was studied in real time up to $30 \mathrm{~min}$. As shown in Table 2, the optimum sodium carbonate concentration at which undesirable pink colour of the layer in the case of blank did not yet appear was of $2.5 \%$. Lower sodium carbonate concentrations reduced the colour intensity and extended the reaction time.

The optimum amount of the NBD-Cl was of $2.5 \mathrm{mg}$ per $\mathrm{g}$ of ground porcelain. Lower contents reduced the colour intensity and higher contents reduced the stability of the filling and resulted in disturbing colour effects. The theoretical reaction molar ratio of NBD-Cl to 2-(dialkylamino)ethanethiols is of $1: 1$, but for the appropriate function of the detector, the ratio of about 10:1 is suitable.

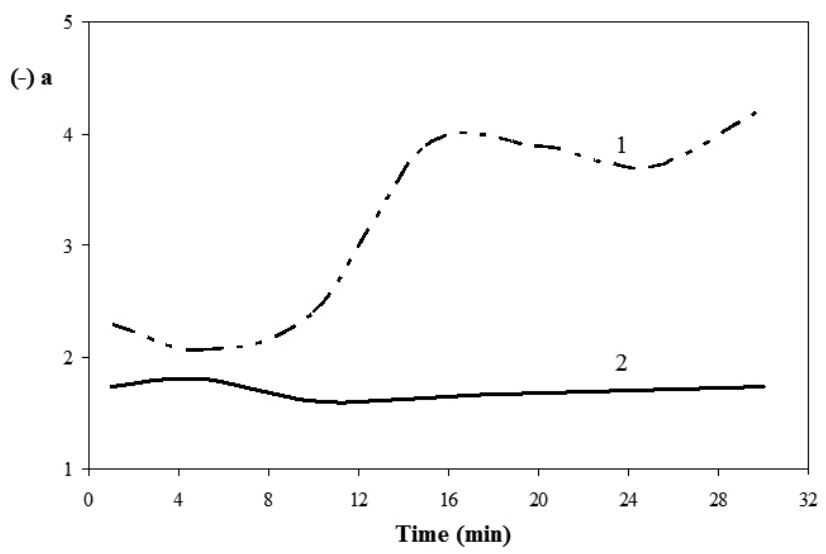

Figure 4. Dependence of detector colour on time (indication layer with $2.5 \% \mathrm{Na}_{2} \mathrm{CO}_{3}$, DEAET concentration $50 \mu \mathrm{g} / \mathrm{ml}$ ), tristimulus colorimetry; (-) $a$ is a negative value of the parameter $a$ (Lab colour system), 1 - DEAET, 2 - blank.

The optimum temperature range for the detection process was found to be of 15 to $30^{\circ} \mathrm{C}$. Within this temperature interval, there was no important effect on the indication layer colour intensity or on the rate of the colour development. At higher temperatures, the analytical reaction was accelerated, but undesirable colour was encountered in blank experiments.

Table 2. Dependence of the detector colour on the $\mathrm{Na}_{2} \mathrm{CO}_{3}$ concentration in indication layer (evaluated after $15 \mathrm{~min}$ ).

\begin{tabular}{|c|c|c|c|c|}
\hline \multirow{2}{*}{$\begin{array}{c}\mathrm{Na}_{2} \mathrm{CO}_{3} \\
\text { concentration, } \\
\%\end{array}$} & \multicolumn{3}{|c|}{ Colour (concentration $100 \mu \mathrm{g} / \mathrm{ml}$ ) } & \multirow[t]{2}{*}{ Blank } \\
\hline & DMAET & DEAET & DIAET & \\
\hline 0 & $\begin{array}{l}\text { Light } \\
\text { yellow } \\
\text { green }\end{array}$ & $\begin{array}{l}\text { Light } \\
\text { yellow } \\
\text { green }\end{array}$ & $\begin{array}{l}\text { Light } \\
\text { yellow } \\
\text { green }\end{array}$ & $\begin{array}{l}\text { Light } \\
\text { yellow }\end{array}$ \\
\hline 1 & $\begin{array}{l}\text { Light } \\
\text { yellow } \\
\text { green }\end{array}$ & $\begin{array}{l}\text { Light } \\
\text { yellow } \\
\text { green }\end{array}$ & $\begin{array}{l}\text { Light } \\
\text { yellow } \\
\text { green }\end{array}$ & $\begin{array}{l}\text { Light } \\
\text { yellow }\end{array}$ \\
\hline 2,5 & Green & Green & Green & $\begin{array}{l}\text { Light } \\
\text { yellow }\end{array}$ \\
\hline 5 & $\begin{array}{l}\text { Dark grey } \\
\text { green }\end{array}$ & $\begin{array}{l}\text { Dark grey } \\
\text { green }\end{array}$ & $\begin{array}{l}\text { Violet } \\
\text { green }\end{array}$ & Light violet \\
\hline 10 & $\begin{array}{l}\text { Dark grey } \\
\text { green }\end{array}$ & $\begin{array}{l}\text { Dark grey } \\
\text { green }\end{array}$ & $\begin{array}{l}\text { Violet } \\
\text { green }\end{array}$ & Light violet \\
\hline 20 & Dark green & Dark green & $\begin{array}{l}\text { Violet } \\
\text { green }\end{array}$ & Light violet \\
\hline
\end{tabular}

3.3. Analytical data

The intensity of the indication layer colour was directly proportional to the 2-(dialkylamino)ethanethiol concentration in water. By using data specified in Table 3 , a colour etalon was established. The detection limit was of $5 \mu \mathrm{g} / \mathrm{ml}$. The upper limit of the visual proportional quantification was of $250 \mu \mathrm{g} / \mathrm{ml}$, which is given by a limited amount of the NBD-Cl reagent in the detector. The method repeatability was tested by repeating the analysis within time periods of one or five days. There were essentially no differences between particular results of analysis based on the visual evaluation. The good visual reproducibility of the method was verified by comparing results obtained in two laboratories. The results have not been supported by objective measurements. During the use of the tristimulus colorimetry method, there were adverse effects due to the inhomogeneity of the liquid sample distribution on the carrier. 
Table 3. Dependence of detector colour on 2-(dialkylamino)ethanethiol concentration ( $2.5 \%$ sodium carbonate), PANTONE Formula Guide ${ }^{21}$.

\begin{tabular}{|c|c|c|}
\hline $\begin{array}{c}\text { DEAET concentration, } \\
\mu \mathrm{g} / \mathrm{ml}\end{array}$ & Colour & PANTONE \\
\hline 0 & Light yellow & $7499 \mathrm{U}$ \\
\hline 5 & Light brown & $7501 \mathrm{U}$ \\
\hline 10 & $\begin{array}{c}\text { Light brown, more } \\
\text { distinct }\end{array}$ & $7502 \mathrm{U}$ \\
\hline 25 & Light green & $585 \mathrm{U}$ \\
\hline 50 & $\begin{array}{c}\text { Light green, more } \\
\text { distinctive }\end{array}$ & $584 \mathrm{U}$ \\
\hline 100 & Green & $583 \mathrm{U}$ \\
\hline 250 & Green brown, intensive & $582 \mathrm{U}$ \\
\hline 500 & Green brown, intensive & $582 \mathrm{U}$ \\
\hline
\end{tabular}

\subsection{Effects of interfering substances}

The reagent is very reactive and presents products of different colours with a number of compounds, including warfare chemical agents. Structurally similar 2-(butyrylamino)ethanethiol, used as stimulant of group V agents, presents orange colour, distinctively different from 2-(dialkylamino)ethanethiols. This suggests that the chromogenic reagent presents different colours with di- and mono- alkylaminoethanethiols. The oxidation products of 2-(dialkylamino) ethanethiols, as e.g. bis(2-diisopropylaminoethyl) sulfide and bisulfide did not yield any colour. Under given reaction conditions, commonly used substrates acetylthiocholine iodide and butyrylthiocholine iodide also did not yield any colour. For an outline of certain interfering substances, which produced different colours with NBD-Cl, see Table 4. Effects of chemical substances, which can be present in waters, were also studied. In these experiments, it was found that the detection of 2-(dialkylamino)ethanethiols is not disturbed by the presence of chlorides, carbonates, sulphates, phosphates, nitrites, thiocyanates, ammonium ions, calcium ions or magnesium ions at concentrations up to 1000 $\mu \mathrm{g} / \mathrm{ml}$. For sulphites and active chlorine, the tolerance limits were of $20 \mu \mathrm{g} / \mathrm{ml}$ and $1 \mu \mathrm{g} / \mathrm{ml}$, respectively.

Table 4. Outline of selected interfering substances, which yielded colour effects with NBD-Cl; the interference factor $\beta$ is a ratio of the detection limi of the disturbing substance and detection limit of 2-(dialkylamino)ethanethiols.

\begin{tabular}{|c|c|c|}
\hline Compound & $\begin{array}{c}\text { Positive test, } \\
\text { colour }\end{array}$ & $\begin{array}{c}\text { Interference } \\
\text { factor } \beta\end{array}$ \\
\hline Sodium sulfide & Red & 5 \\
\hline 2-(butyrylamino)ethanethiol & Orange & 1 \\
\hline 2-(dimethylamino)ethanol & Pink & 25 \\
\hline Hydroxylamine & Violet & 10 \\
\hline Lewisite & Blue & 10 \\
\hline CS agent & Violet red & 5 \\
\hline CN agent & Violet red & 5 \\
\hline
\end{tabular}

3.5. Effects of organic solvents

A principal study of effects of certain water-miscible organic solvents was implemented. Particularly polar protic solvents, ethanol and methanol, and aprotic solvents, acetone, dimethylsulphoxide (DMSO) and $N N$ dimethylformamide (DMFA) were studied. The study demonstrated considerable effects of these solvents on the colour shade of the reaction product and increase in the colour intensity. It also revealed beneficial effects on the reaction rate and colour stability in the indication layer. At a concentration of $50 \mu \mathrm{g} / \mathrm{ml}$, the 2-(dialkylamino)ethanethiol samples produced blue to green colour in the presence of organic solvents, the intensity of which was directly proportional to the solvent contents. In equilibrium mixtures (50:50), the colours obtained were dark blue with methanol, ethanol and acetone, dark blue-green with DMSO, and dark green with DMFA. Higher solvent contents resulted in undesirable blank colours. The presence of organic solvents at concentrations below $1 \%$ exerted essentially no colour effects. Effects of certain solvents on the colour of the indication layer exposed to DEAET is depicted in Figure 5, which offers a comparison of curves of the reflexion factor depending on the wave length (as measured by the tristimulus colorimeter).

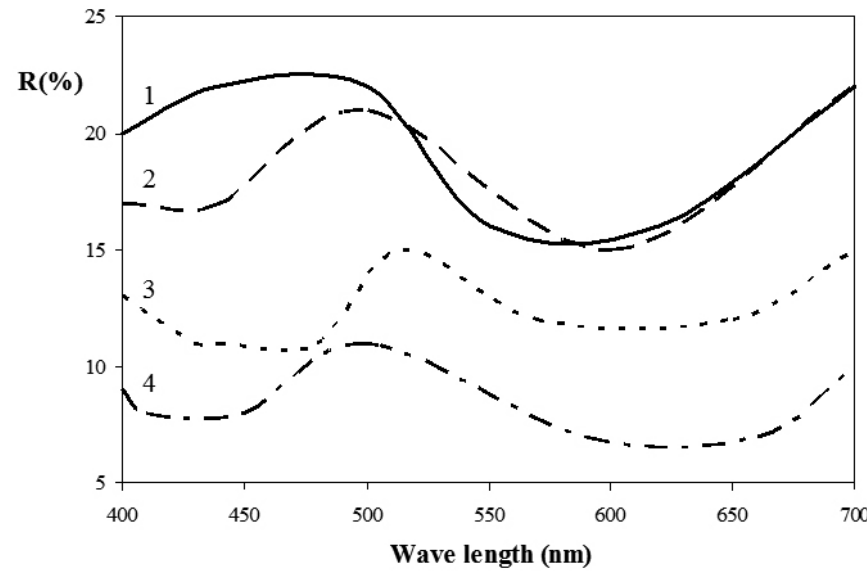

Figure 5. Reflexion curves of reaction products depending on additions of organic solvents; $\mathrm{R}$ - reflexion factor, 1 - methanol, 2 - acetone, 3 - DMFA, 4 - DMSO

3.6. Filling stability and detector life time

Stability of silica gel filling impregnated with sodium carbonate is essentially unlimited. The porcelain filling with the NBD-Cl applied is stable and can be stored for a long period of time at temperatures up to $30^{\circ} \mathrm{C}$. In enclosed amber glass powder bottles it saves its original characteristics for a period of at least one year. The shelf life of the complete colorimetric detector tube is at least the same.

\subsection{Applications}

Water samples were taken from different sources, processed by adding known amounts of 2-(dialkylamino)ethanethiols and analyzed by using the detector designed here in a common way. The results were compared with the standard spectrophotometric method with triphenylmethane dye Malachite Green ${ }^{13}$. The values obtained in the detection of 2-(dialkylamino)ethanethiols in real samples were essentially identical with those obtained by their analysis in distilled water. The statistical analysis demonstrated no significant differences between results achieved by the orientational method proposed and standard spectrophotometric method (Table 5).

Table 5. Results of detection of real samples by the detector proposed (visual evaluation) and by the reference (spectrophotometric) method; R recovery.

\begin{tabular}{|c|c|c|c|c|c|}
\hline \multirow{2}{*}{ Sample } & \multirow{2}{*}{$\begin{array}{c}\text { Added } \\
\mu \mathrm{g} / \mathrm{ml}\end{array}$} & \multicolumn{2}{|c|}{ Method proposed } & \multicolumn{2}{c|}{ Reference method } \\
\cline { 3 - 6 } & $\begin{array}{c}\text { Found, } \\
\mu \mathrm{g} / \mathrm{ml}\end{array}$ & $\mathrm{R}, \%$ & $\begin{array}{c}\text { Found, } \\
\mu \mathrm{g} / \mathrm{ml}\end{array}$ & $\mathrm{R}, \%$ \\
\hline \multirow{2}{*}{ DMAET } & 12.5 & 10 & 80.0 & 8.9 & 71.2 \\
\cline { 2 - 6 } & 55.4 & 50 & 90.3 & 51.5 & 93.0 \\
\hline \multirow{2}{*}{ DEAET } & 13.1 & 10 & 76.3 & 9.8 & 74.8 \\
\cline { 2 - 6 } & 21.7 & 25 & 115.2 & 19.9 & 91.7 \\
\hline \multirow{2}{*}{ DIAET } & 32.1 & 25 & 77.9 & 30.2 & 94.1 \\
\cline { 2 - 6 } & 56.7 & 50 & 88.2 & 53.1 & 93.7 \\
\hline
\end{tabular}

\section{CONCLUSION}

The new method of the semiquantitative determination of 2-(dialkylamino) ethanethiols in water with the help of a colorimetric detector tube is simple and selective. The detector proposed is suitable for its use in the field and in laboratories for the control of the presence of precursors of V-type nerve agents or of their hydrolytic products. Chemical reagents NBD-Cl and sodium carbonate applied onto ground porcelain or silica gel are stable and in the presence of 2-(dialkylamino)ethanethiols, they yield characteristic green colour, distinctively different from the colour produced with monoalkylaminoethanethiols, certain warfare chemical agents and industrial pollutants. The detection limit was of $5 \mu \mathrm{g} / \mathrm{ml}$. The method is reproducible and sufficiently precise. No processing of the samples analyzed is required. The 
presence of certain polar organic solvents (ethanol, methanol, acetone, DMSO or DMFA) exerts positive effects on the detection limit, speed of the analysis and stability of the indication effect (colour).

\section{ACKNOWLEDGEMENT}

The work originated within the framework of the safety research project of the Ministry of Internal Affairs of the Czech Republic No. VG 20102013048 and project for supporting the development of the organization of the Ministry of Defence of the Czech Republic.

\section{REFERENCES}

1. R. Zajtchuk, R.F. Bellamy eds. Medical aspects of chemical and biological warfare, Borden Institute, Walter Red Army Medical Center, Washington, 1997; pp. 131-139.

2. S.L. Hoenig. Compendium of chemical warfare agents, Springer Science, New York, 2007; pp. 77-128.

3. D.H. Ellison. Handbook of chemical and biological warfare agents, CRC Press, New York, 2008.

4. V.S. Mirzayanov. State secrets, An insider's chronicle of Russian chemical weapons program, Outskirts Press, Denver, 2009.

5. S.J. Smith, Talanta 30, 725 (1983).

6. R.H. Poirier, R.D. Morin, S.J. Kiehl, R.W. Pfeil, A.E. Bearse. Detection of V-agents, Eleventh montly progress report, Battelle Memorial Institute, 1957.
7. V. Pitschmann, L. Matejovsky, Z. Kobliha, Mil. Med. Sci. Lett. (Voj. Zdrav. Listy) 82, 149 (2013).

8. S. Royo, R. Martínez-Máñez, F. Sancenón, A.M. Costero, M. Parra, S. Gil, Chem. Commun. 4839 (2007)

9. K. Kim, O.G. Tsay, D.A. Atwood, D.G. Churchill, Chem. Rev. 111, 5403 (2011).

10. G.L. Ellman, Arch. Biochem. Biophys. 74, 443 (1958).

11. G.L. Ellman, Arch. Biochem. Biophys. 82, 70 (1959).

12. I.O.C. Egwim, H.J. Gruber, Anal. Biochem. 288, 188 (2001).

13. E. Halámek, Z. Kobliha, Z. Skaličan, Sborník VVŠ PV (Technické a př́rodní vědy) 237 (1998).

14. D.J. Birkett, N.C. Price, G.K. Radda, A.G. Salmon, FEBS Letters 6, 346 (1970).

15. M. Shipton, T. Stuchbury, K. Brocklehurst, Biochem. J. 159, 235 (1976).

16. D. Eastwood, L.J. Cline Love eds. Progress in analytical luminiscence, ASTM, New York, 1988.

17. A.A. Elbashir, F.E.O. Suliman, H.Y. Aboul-Enein, Appl. Spectros. Rev. 46, $222(2011)$.

18. A. Önal, Quim. Nova 34, 677 (2011).

19. T. Čapoun, J. Krykorková, Informační zpravodaj Institutu ochrany obyvatelstva 13, 10 (2002).

20. K. Nitta, S.C. Bratcher, M.J. Kronman, Biochem. J. 177, 385 (1979).

21. PANTONE Color System Formula Guide. Pantone, 2006. 